archives

of thermodynamics

Vol. 38(2017), No. 2, 61-79

DOI: $10.1515 /$ aoter-2017-0010

\title{
System effects of primary energy reduction connected with operation of the CHP plants
}

\author{
ANDRZEJ ZIĘBIK* \\ PAWEE GEADYSZ
}

Silesian University of Technology, Institute of Thermal Technology, Konarskiego 22, 44-100 Gliwice

\begin{abstract}
The paper is devoted to explication of one of the advantages of heat and electricity cogeneration, rarely considered in technical literature. Usually attention is paid to the fact that heat losses of the heat distribution network are less severe in the case of cogeneration of heat in comparison with its separate production. But this conclusion is also true in other cases when the internal consumption of heat is significant. In this paper it has been proved in the case of two examples concerning trigeneration technology with an absorption chiller cooperating with a combined heat and power (CHP) plant and CHP plant integrated with amine post-combustion $\mathrm{CO}_{2}$ processing unit. In both considered cases it might be said that thanks to cogeneration we have to do with less severe consequences of significant demand of heat for internal purposes.
\end{abstract}

Keywords: Cogeneration; Trigeneration; Amine $\mathrm{CO}_{2}$ capture; System effects

\section{Nomenclature}

$$
\begin{array}{lll}
E & - & \text { energy } \\
f g & - & \text { flue gases } \\
Q & - & \text { heat } \\
q & - & \text { unit consumption of heat }
\end{array}
$$

\footnotetext{
*Corresponding Author. Email andrzej.ziebik@polsl.pl
} 


\section{Greek symbols}

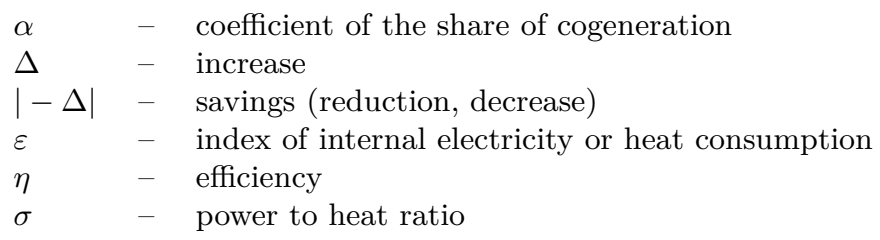

\section{Subscripts}

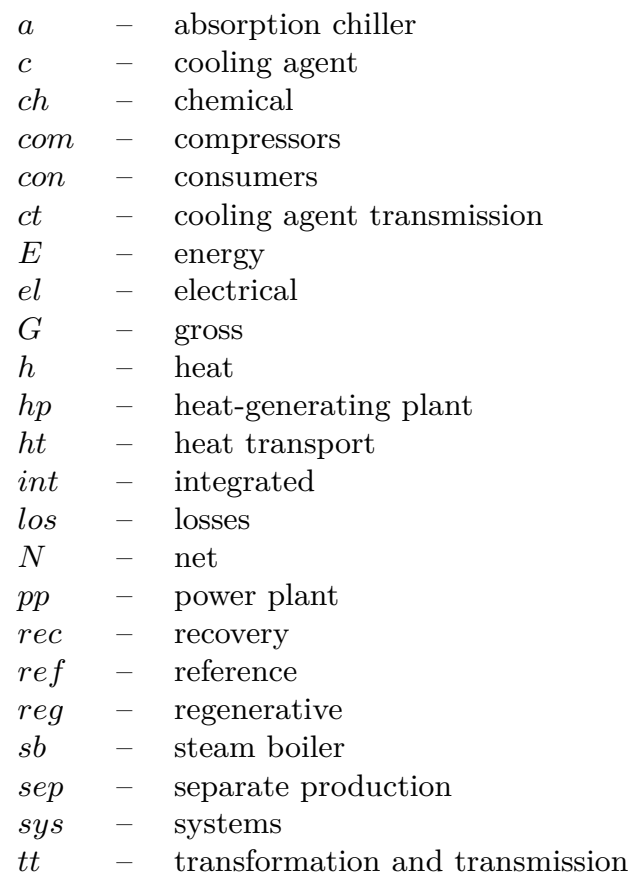

\section{Abbreviations

$C C S-\mathrm{CO}_{2}$ capture and storage
$C H P-$ combined heat and power
$C O P-$ coefficient of performance
$C P U-\mathrm{CO}_{2}$ processing unit

\section{Introduction}

The municipal and industrial thermal processes can be usually provided with heat from the combined heat and power (CHP) units or heat-generating plants by means of heat distribution network. Losses of heat during transmission as well as consumption of heat in additional installations as for instance absorption chiller in trigeneration (or combined cooling, heat and 
power - CCHP) technology or desorber in amine $\mathrm{CO}_{2}$ processing unit cause the increase of internal consumption of heat and in consequence increase of fuel consumption. Partial compensation of the increased internal consumption of heat takes place in the CHP units because electricity is cogenerated as a by-product deciding about the system effects of the reduction of primary energy consumption. This problem has been highlighted in [1], where heat losses during transmission of heat from the CHP plants or heatgenerating plants by heat distribution network have been analysed. The essence of this problem is a perception of the fact that although heat losses cause additional consumption of the chemical energy of fuels in the CHP plant (local effect), on the other hand, however, the production of electricity grows and increases primary energy savings thanks to cogeneration (system effects). Thus the final result is positive. This effect does not take place in the case of the production of heat in a heat-generating plant. It should also be stressed that the system effect of primary energy reduction thanks to cogeneration is recorded not directly in the CHP plant but on the level of the national energy system.

The first author of this considerations paid attention in his earlier papers to the fact that the same effect can also be observed in the case of trigeneration technology with the absorption chiller $[2,3]$. Similarly as in the previous case, this effect is caused by the production of electricity in cogeneration with the production of heat for the absorption chiller. The index of the savings of chemical energy of fuel in the trigeneration system grows with decreasing of the coefficient of performance (COP) of the absorption chiller. It should not however be understood that the worse COP, leads to elevated savings. It means, however, that cooperation of the absorption chiller with the cogeneration system (CHP plant) causes less severe consequences of the worse $\mathrm{COP}$ of the absorption chiller if the demand for driving heat is realized by the CHP plant [3].

Large internal users of heat are systems of $\mathrm{CO}_{2}$ capture and storage (CCS), particularly with post-combustion $\mathrm{CO}_{2}$ capture [4]. In the case of CHP-CCS systems the internal demand for regeneration heat in $\mathrm{CO}_{2}$ capture unit is realized by the bleeders of the extraction-condensing turbine or outlet steam from the back-pressure turbine. Due to this, a growth of gross production of electricity in cogeneration has been observed. But on the other hand, the internal consumption of electricity increases because of driving the $\mathrm{CO}_{2}$ compressors as well as pumps and fans in $\mathrm{CO}_{2}$ processing unit. Finally, the net production of electricity in cogeneration has been 
decreased but this reduction is lower, the greater is the demand for heat concerning regeneration of solvent. This is also a system effect of primary energy reduction due to cogeneration technology $[5,6]$.

The algorithms of the aforesaid above three cases of system effects of primary energy reduction connected with power and heat cogeneration technology are presented in this paper. For each case the results of exemplary calculations confirming the thesis described in algorithmic part of the paper have also been presented. It should be noticed that generally the useful effect of heat and electricity cogeneration being a primary energy savings is not observed locally in a CHP plant because this is a system effect $[7,8]$. Direct savings of the chemical energy of fuels takes place in a system power plant in which some part of electricity production has been replaced by production of the CHP plant. Including consumption of energy during extraction, processing and transport of fuels we can evaluate cumulative energy savings on the level of national energy system [8].

\section{Partial compensation of chemical energy consumption of fuel charging the heat losses in heat distribution network supplied from CHP plant}

Every loss of heat in the heat distribution network cooperating with a heatgenerating plant or a CHP plant causes a growth of the gross production of heat. In consequence, the consumption of chemical energy of fuel increases. In the case of heat-generating plant the increase of the consumption of the chemical energy of fuel connected with additional production of heat due to heat losses is as follows:

$$
\Delta E_{c h h p}=\frac{Q_{l o s}}{\eta_{E h p} G},
$$

where:

$\Delta E_{c h h p}-$ additional consumption of the chemical energy of fuels in heat-generating plant due to heat losses,

$Q_{\text {los }} \quad-$ heat losses in heat distribution network,

$\eta_{E h p G} \quad-$ gross energy efficiency of heat-generating plant.

Thus, when heat distribution network are fed from the heat-generating plant the heat losses cause directly the increase of the consumption of 
chemical energy of fuels.

Heat losses in the heat distribution network cooperating with CHP plant also lead to increasing the consumption of chemical energy of fuel locally in CHP plant but simultaneously increase the cogeneration of electricity and in result we can observe decreasing the consumption of the chemical energy of fuels in the replaced power plant due to substituting the some part of its electricity production by the CHP plant. The system effect of these operations is calculated by means of the equation

$$
\Delta E_{\text {ch sys }}=\Delta E_{\text {ch CHP }}-\left|-\Delta E_{\text {ch } p p}\right|,
$$

where:

$\Delta E_{\text {ch sys }} \quad-\quad$ system effect of increasing the consumption of the chemical energy of fuels in the case of CHP plant cooperating with heat distribution network,

$\triangle E_{\text {ch CHP }} \quad-\quad$ increase of the consumption of the chemical energy of fuel in the CHP plant,

$\left|-\Delta E_{\text {ch } p p}\right|-$ decrease of the chemical energy of fuel consumption in the replaced power plant due to cogeneration of heat and electricity.

The increase of the consumption of the chemical energy of fuels due to heat losses, concerning CHP plant, is as follows:

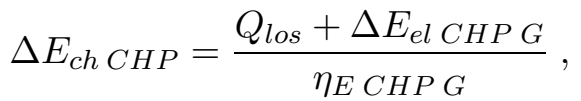

where:

$\triangle E_{\text {el } C H P G}-$ increase of gross electricity production in cogeneration of heat covering the heat losses,

$\eta_{E C H P G} \quad-$ gross energy efficiency of a CHP plant.

Assuming that the efficiencies of transformation and transmissions of electricity are the same in the case of power plant and CHP unit the decrease of the consumption of the chemical energy of fuels in a system power plant due to replacing the part of electricity production by a CHP plant results from the equation

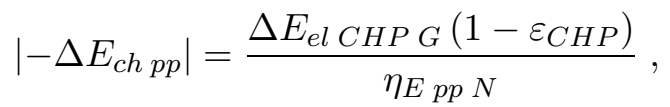

where:

$\eta_{E \text { pp } N}-$ net energy efficiency of the replaced power plant,

$\varepsilon_{C H P}-$ index of internal electricity consumption concerning CHP plant. 
Including Eqs. (3) and (4) into Eq. (2) we get a formula concerning system increase of the chemical energy of fuels in the case of cogeneration:

$$
\Delta E_{\text {ch sys }}=Q_{\text {los }}\left[\frac{1+\sigma}{\eta_{E C H P G}}-\frac{\sigma\left(1-\varepsilon_{C H P}\right)}{\eta_{E p p ~}}\right],
$$

where $\sigma$ denotes power to heat ratio.

Reduction of the consumption of chemical energy of fuels, charging the heat losses in heat distribution network, due to cogeneration of heat and electricity in comparison with the separate production of heat results from the equation:

$$
\left|-\Delta E_{c h}\right|=\Delta E_{\text {ch } h p}-\Delta E_{\text {ch sys }},
$$

where $\left|-\Delta E_{c h}\right|$ denotes energy savings of the chemical energy of fuels due to cogeneration.

In Eq. (6) it was assumed that the change of electricity consumption for heat transmission due to the change of heat losses is nearly the same in both considered cases, namely cogeneration and separate production of heat in heat generating plant. As the partial efficiency of electricity production in a CHP plant is the same as efficiency of electricity production in system power plant $[8,9]$ the changes of the consumption of the chemical energy of fuel in the case of heat transmission from heat generating plant and in the case of CHP plant are the same. Therefore both these items included into Eq. (6) are reduced.

Introducing Eqs. (1) and (5) into Eq. (6) and referring energy savings to heat losses we have

$$
\frac{\left|-\Delta E_{c h}\right|}{Q_{l o s}}=\frac{1}{\eta_{E h p} G}-\frac{1}{\eta_{E C H P G}}+\sigma\left(\frac{1-\varepsilon_{C H P}}{\eta_{E p p N}}-\frac{1}{\eta_{E C H P G}}\right) .
$$

The following input data have been assumed in the analysis: $\eta_{E} h_{p} G=0.85$, $\eta_{E \text { pp } N}=0.43$, and $\varepsilon_{C H P}=0.11$. The analysis has been carried out in the following ranges of $\eta_{E C H P} G$ and $\sigma: 0.75-0.85$, and $0.3-0.5$, respectively. Figure 1 presents the reduction of consumption of chemical energy of fuels covering the heat losses in heat distribution network supplied from CHP plant. This effect of partial compensation of chemical energy of fuels connected with heat losses depends on the gross energy efficiency of CHP plant and power to heat ratio. The higher values of those parameters the higher system effects (reduction of chemical energy consumption) thanks to cogeneration. Generally we can say that heat losses connected with the 


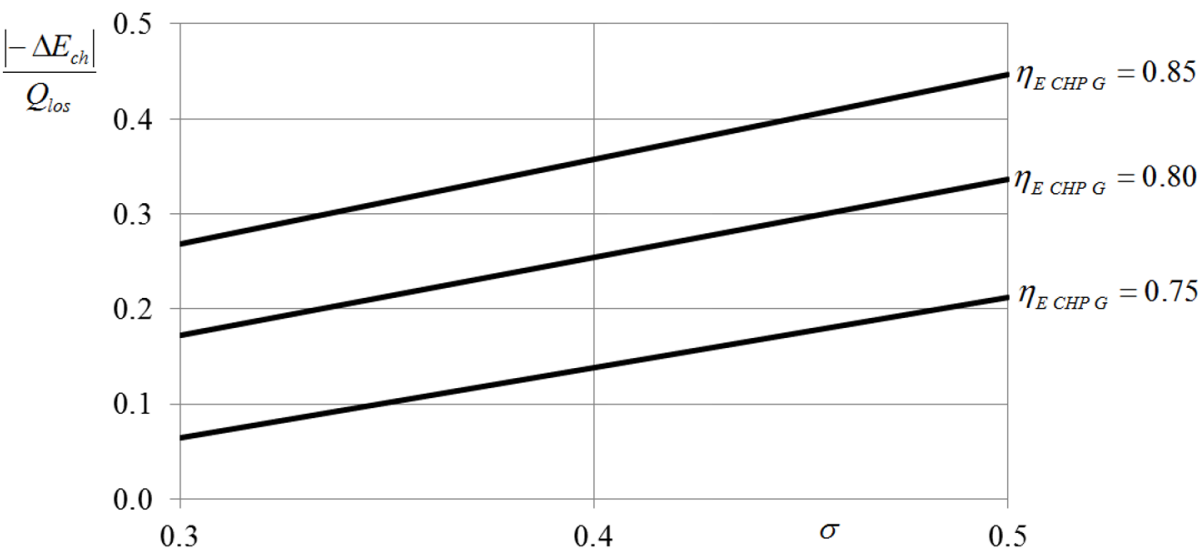

Figure 1: Reduction of the consumption of chemical energy of fuels covering heat losses by cogeneration.

transmission of heat by means of heat distribution network are less severe in the case of its cooperation with CHP plant in comparison with supply the heat distribution network from heat generating plant [9].

\section{System effects of primary energy reduction in trigeneration installations}

Combination of a CHP plant with centralized system of cooling agent production [10] is called 'trigeneration'. This consideration is devoted to an installation equipped with absorption chiller driven by heat from CHP plant. Figure 2 presents a scheme of a classical CHP plant cooperating with the centralized system of cooling agent production.

The additional gross production of heat dedicated to production of cooling agent in a CHP plant and additional gross cogeneration of electricity are charged by the additional consumption of the chemical energy of fuels:

$$
\Delta E_{c h C H P}=\frac{Q_{c \text { con }}(1+\sigma)}{\eta_{E C H P G} \eta_{c t}\left(1-\varepsilon_{c}\right) C O P_{a}}
$$

where: 


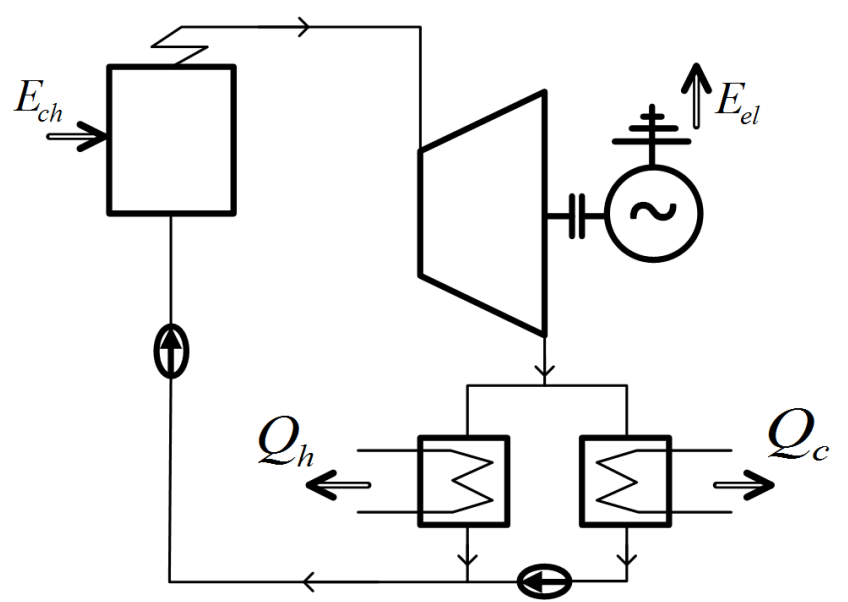

Figure 2: Scheme of a CHP unit with a centralized system of providing the cooling agent: $E_{c h}$ - chemical energy of fuel, $E_{e l}$ - production of electricity, $Q_{h}$ - production of heat, $Q_{c}$ - production of cooling agent.

$$
\begin{aligned}
& \Delta E_{\text {ch CHP }}-\text { additional consumption of the chemical energy of fuels in } \\
& \text { a CHP plant due to production of cooling agent, } \\
& Q_{c \text { con }} \quad-\text { amount of cooling agent by the consumers, } \\
& \sigma \quad-\text { power to heat ratio, }
\end{aligned}
$$

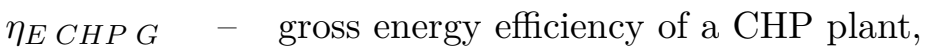

$$
\begin{aligned}
& \eta_{c t} \quad-\text { efficiency of cooling agent transmission from CHP plant, } \\
& \varepsilon_{c} \quad-\text { own consumption of cooling agent in a CHP plant, } \\
& \mathrm{COP}_{a}-\text { coefficient of performance of absorption chiller. }
\end{aligned}
$$

In the case of separate production of the cooling agent in cooperation with a heat-generating plant and electricity production in the system power plant the consumption of chemical energy of fuels is as follows:

$$
E_{c h ~ s e p}=\frac{Q_{c c o n}}{\eta_{E h p G} \eta_{c t}^{\prime}\left(1-\varepsilon_{c}^{\prime}\right) C O P_{a}}+\frac{\sigma Q_{c c o n}\left(1-\varepsilon_{e l}\right) \eta_{t t}}{\eta_{E p p ~} \eta_{c t}\left(1-\varepsilon_{c}\right) C O P_{a} \eta_{t t}^{\prime}},
$$

where:

$E_{\text {ch sep }} \quad-\quad$ consumption of chemical energy of fuels charging the separate production of cooling agent and electricity,

$\eta_{E h p G}-$ gross energy efficiency of heat-generating plant,

$\eta_{c t}, \eta_{c t}^{\prime} \quad$ - efficiency of cooling agent transmission from CHP plant and heat generating plant, 

$\varepsilon_{c}^{\prime} \quad-$ own consumption of cooling agent in heat-generating plant,
$\eta_{E p p N}-$ net energy efficiency of a systems power plant,
$\varepsilon_{e l} \quad-$ own consumption of electricity in a CHP plant,
$\eta_{t t}, \eta_{t t}^{\prime} \quad-$ efficiency of transformation and transmission of electric- ity from CHP plant and systems power plant.

Assuming that $\eta_{t t}=\eta_{t t}^{\prime}$ and neglecting the own consumption of the cooling agent and its losses during transmission the savings of chemical energy of fuel results from the comparison of 'trigeneration' system with a separate production of heat, cooling agent and electricity is as follows:

$$
\frac{\left|-\Delta E_{c h}\right|}{Q_{c c o n}}=\frac{1}{C O P_{a}}\left[\frac{1}{\eta_{E h p} G}-\frac{1}{\eta_{E C H P G}}+\sigma\left(\frac{1-\varepsilon_{e l}}{\eta_{E p p N}}-\frac{1}{\eta_{E C H P G}}\right)\right] .
$$

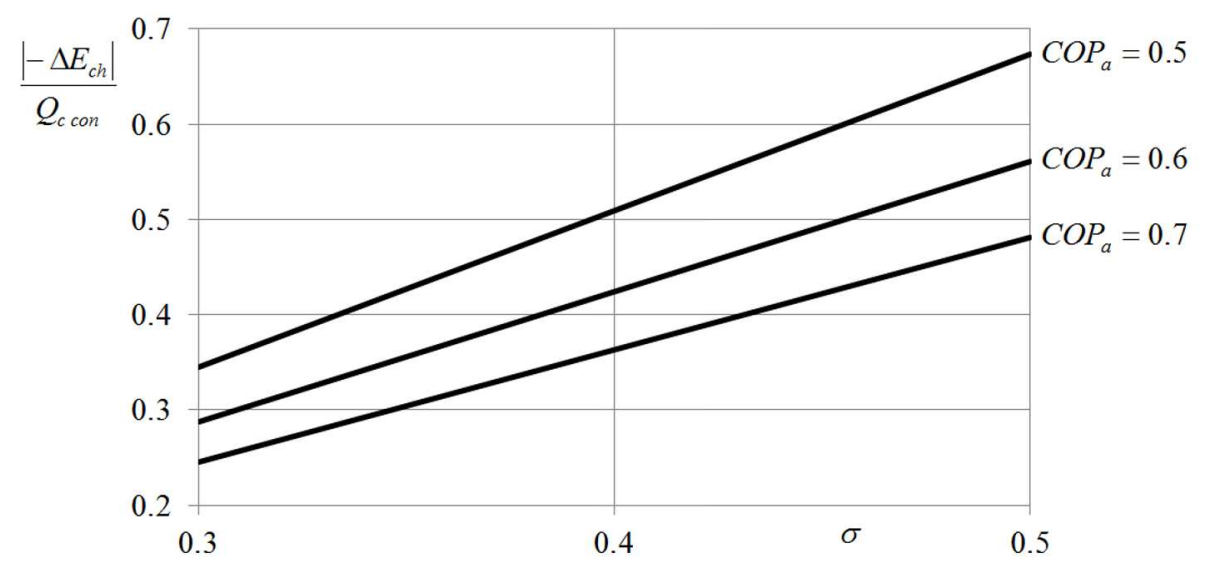

Figure 3: Energy savings of the chemical energy of fuels due to trigeneration.

Figure 3 presents energy savings of chemical energy of fuel thanks to the production of cooling agent in the absorption chiller in cooperation with the CHP plant (trigeneration technology). These savings result from replacing the electricity production in a system power plant, thanks to additional production of electricity in cogeneration, with additional heat demand for absorption chiller. It is natural that the energy savings increase with increasing power to heat ratio but the growth with the decreasing $C O P_{a}$ of the absorption chiller needs explanation. This tendency cannot be interpreted that the worse efficiency is better. It merely means that the production of 
heat in cogeneration with electricity partially compensates worse $C O P_{a}$ of the absorption chiller $[2,3]$.

\section{System effect of partial compensation of the increased own consumption of heat in a CHP plant integrated with an amine $\mathrm{CO}_{2}$ processing unit}

The post-combustion $\mathrm{CO}_{2}$ capture based on amine solvent belongs at present to the most technically mature ways of $\mathrm{CO}_{2}$ removal [11-14]. The weak side of this method is a high demand for heat in order to regenerate the solvent. Figure 4 presents scheme of CHP plant integrated with $\mathrm{CO}_{2}$ processing unit (CPU) and installation of waste heat recovery. CPU consists of $\mathrm{CO}_{2}$ absorption column and desorption column [13]. Desorption column serves to the regeneration of aqueous solution of mixture containing monoethanoloamine, dieethanoloamine and methyldieethanoloamine. This process in desorber requires additional production of heat for internal consumption. The process heat for this purpose is transported from the bleeds of the extraction-condensing steam turbine or from the outlet of backpressure turbine with a pressure of about $0.2 \mathrm{MPa}$. It provides required range of temperature regeneration. In [12] attention has been paid to the considerable consumption of heat concerning amine regeneration. In this consideration, the unit consumption of heat for regenerative purposes has been assumed: $4,3.4$, and $3.15 \mathrm{MJ} / \mathrm{kg} \mathrm{CO}$. The first value concerns traditional installations existing up to now whereas the second one is treated as a value possible to be achieved today. The third value can be treated as a value in the nearest future confirmed by several research works [15-19].

It should be stressed that the CPU installation is not only consumer of process heat but also is a source of waste heat in which recovery may cover partially the demand for system of the heat distribution network (district or industrial). The source of waste heat is the process of $\mathrm{CO}_{2}$ desorption in which the condensation of $\mathrm{H}_{2} \mathrm{O}$ takes place. Also, the installation of interstage cooling of $\mathrm{CO}_{2}$ compressors are sources of waste heat.

Similarly as in previous subsections the growth of internal consumption of heat for the purpose of solvent regeneration in the CHP plant leads to an increase of the electricity production. But in this case the situation is more complicated because simultaneously the demand for electricity growths due 


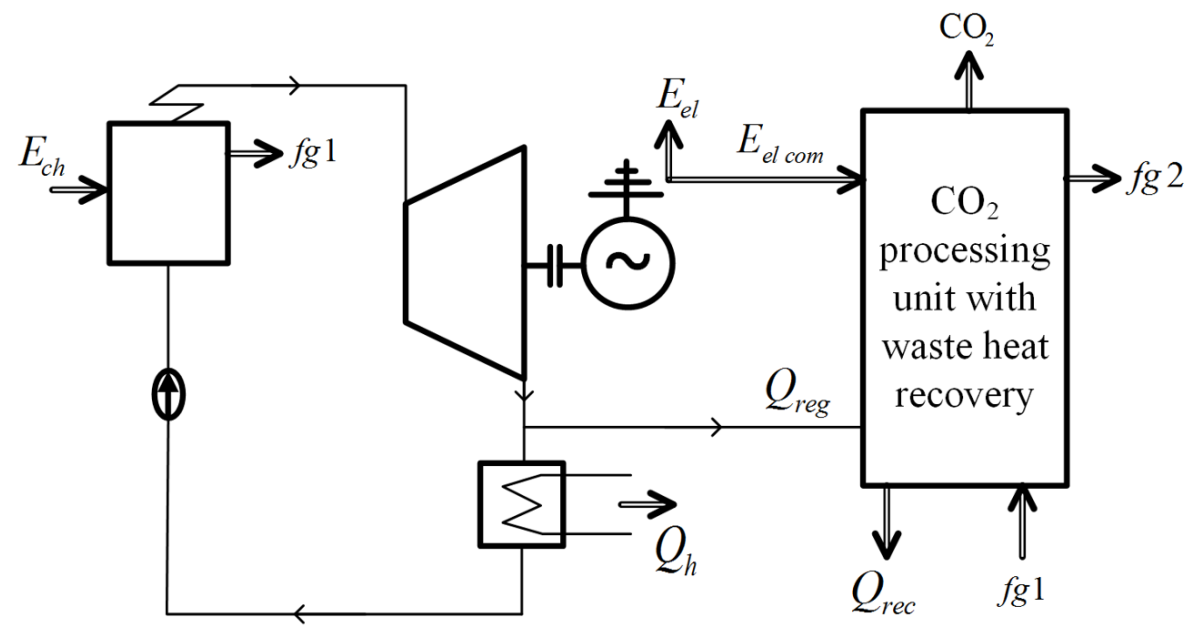

Figure 4: Scheme of a CHP plant integrated with $\mathrm{CO}_{2}$ processing unit and installation of waste heat recovery: $E_{c h}$ - chemical energy of fuel, $f g$ - flue gases, $E_{e l}-$ electricity for external consumers, $E_{\text {elcom }}$ - electricity for $\mathrm{CO}_{2}$ compressors, $Q_{r e g}$ - regenerative heat, $Q_{h}$ - heat for external consumers, $Q_{r e c}-$ heat from waste energy recovery.

to driving the $\mathrm{CO}_{2}$ compressors in CPU. Additionally, waste heat recovery from CPU leads to a reduction of the demand for low-pressure heating steam from the turbine and in consequence the production of electricity cogenerated with low-pressure heating steam has been decreased. Such the thermodynamic analysis characterizes the greater complexity than in the cases presented previously. That is why simulation models were prepared by means of the commercial engineering software Thermoflex [20]. This software allows to construct requisite models of the analysed energy system based on predefined components available in the library of Thermoflex. The components are among others group of turbine stages, compressors, pumps, heat exchangers of regeneration and heat engineering and also for instance the installation of $\mathrm{CO}_{2}$ processing unit. Simulation models have been constructed not only as a design mode but also as off-design one. Annual duration curve of outdoor temperature and the characteristics of the heat distribution network have been applied in the simulation calculations $[5,6]$.

First of all the reference CHP plant with an extraction-back-pressure turbine and CFB peak boiler (without CPU) has been modeled. In this case the index of savings of chemical energy of fuel is calculated from the 
formula $[6]$

$$
\begin{aligned}
& \left(\frac{\left|-\Delta \dot{E}_{c h}\right|}{\dot{Q}_{c o n}}\right)_{r e f}= \\
& \frac{\alpha_{c o g}}{\eta_{h t}}\left[\frac{1}{\left(1-\varepsilon_{h h p}\right) \eta_{E h p G}}+\frac{\sigma_{r e f}\left(1-\varepsilon_{e l ~ r e f}\right)}{\left(1-\varepsilon_{h r e f}\right) \eta_{E p p ~}}-\frac{1+\frac{\sigma_{r e f}}{\eta_{m e}}}{\left(1-\varepsilon_{h r e f}\right) \eta_{E s b}}\right] \text {, }
\end{aligned}
$$

where:

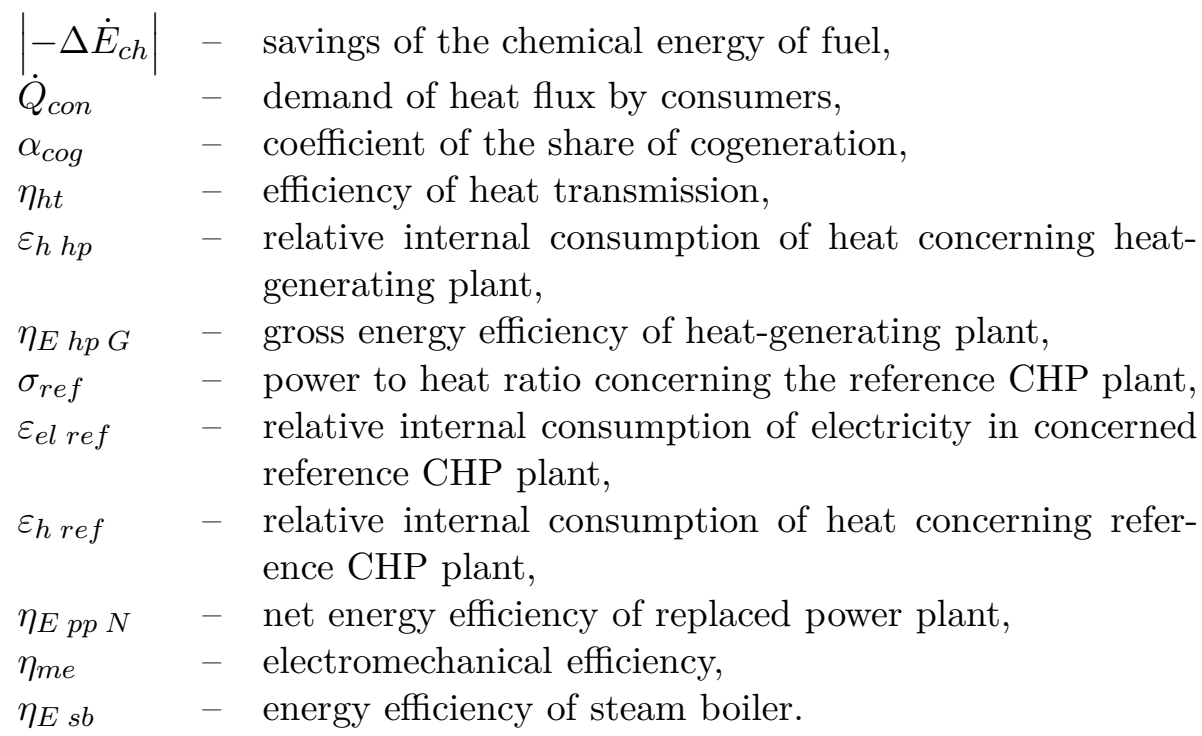

Next, the model of the CHP plant with back-pressure turbine and $\mathrm{CO}_{2}$ processing unit has been elaborated. The additional desulphurization system must be installed due to requirement of amine $\mathrm{CO}_{2}$ processing unit. The compressors station of $\mathrm{CO}_{2}$ has been equipped with four units. Waste heat from interstage cooling of $\mathrm{CO}_{2}$ compressors has been utilized in the basic heat exchanger of district heating system. In order to regenerate the amine solution, the $\mathrm{CO}_{2}$ processing unit is fed by the process steam from the outlet of back-pressure turbine. The index of savings of chemical energy of fuel is as follows [6]:

$$
\begin{aligned}
& \left(\frac{\left|-\Delta \dot{E}_{c h}\right|}{\dot{Q}_{c o n}}\right)_{i n t}=\frac{\alpha_{c o g}}{\eta_{h t}}\left[\frac{1}{\left(1-\varepsilon_{h h p}\right) \eta_{E h p G}^{i n t}}-\frac{1}{\left(1-\varepsilon_{h i n t}\right) \eta_{E \operatorname{cog} G}^{i n t}}\right]+ \\
& +\sigma_{i n t}\left[\frac{\alpha_{c o g}}{\left(1-\varepsilon_{h i n t}\right) \eta_{h t}}-\frac{\dot{Q}_{r e c}}{\dot{Q}_{c o n}}+\frac{\dot{Q}_{r e g}}{\dot{Q}_{c o n}}\right]\left[\frac{\left(1-\varepsilon_{e l ~ i n t}\right)}{\eta_{E p p N}^{i n t} N}-\frac{1}{\eta_{E \operatorname{cog} G}^{i n t}}\right]
\end{aligned}
$$


where:

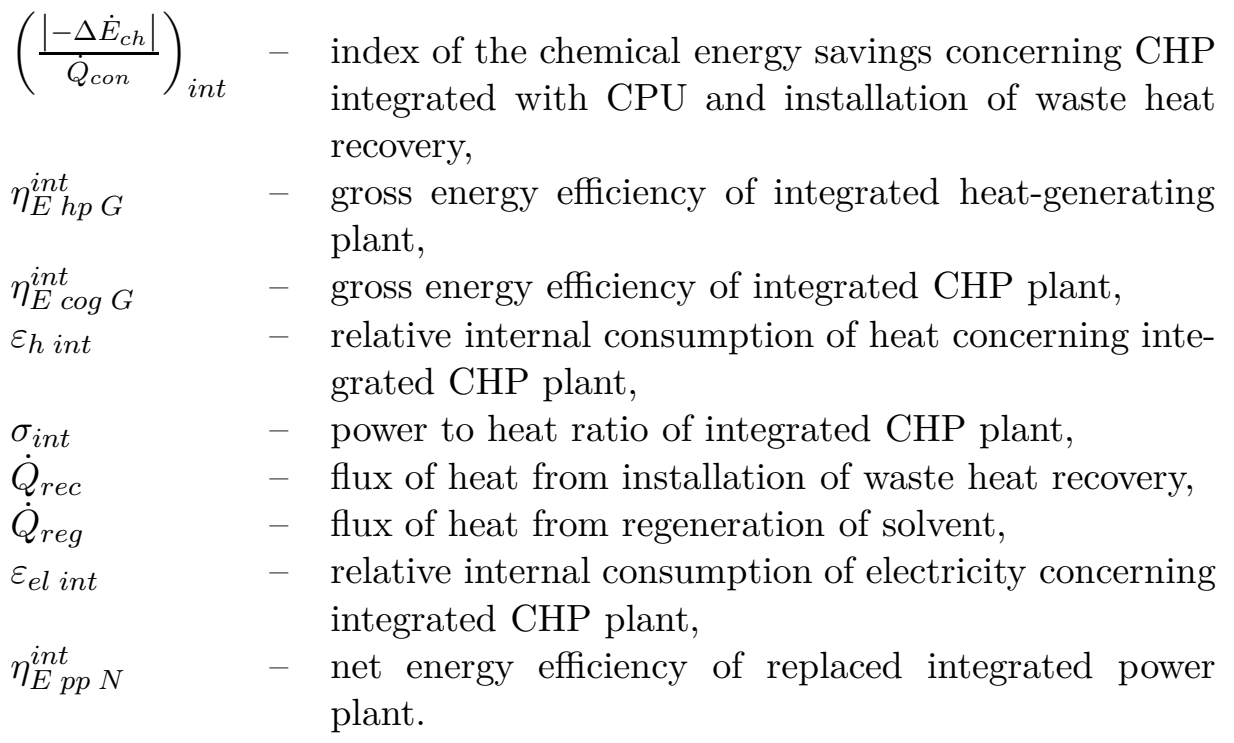

Table 1 presents the results of simulation analysis concerning the CHP plant integrated with amine $\mathrm{CO}_{2}$ processing unit and waste heat recovery installation $[5,6]$. The following additional input data have been used in an analysis:

- unit consumption of the chemical energy of fuel and production of electricity in a reference CHP plant (without $\mathrm{CO}_{2}$ removal) with reference to heat by consumers $-E_{\text {ch ref }} / Q_{c o n}=1.1665 \mathrm{~J} / \mathrm{J}$ and $E_{\text {el ref }} / Q_{\text {con }}=0.3446 \mathrm{~J} / \mathrm{J}$,

- net efficiency of replaced integrated power plant $-\eta_{E p p N}^{i n t}=0.334$,

- index of the chemical energy savings concerning the reference CHP plant with reference to heat by the consumers $-\left|-\Delta E_{\text {ch ref }}\right| / Q_{c o n}=$ $0.381 \mathrm{~J} / \mathrm{J}$.

The additional demand for internal consumption of heat in CPU installation connected with the regeneration of the solvent in CPU installation causes, of course, an additional consumption of the chemical energy of fuel but on the other hand the electricity additionally cogenerated with heat for regeneration of solvent influences the reduction of the chemical energy consumption concerning systems power plant due to decrease of its electricity production (effect of replacement). The CPU installation operates together with the $\mathrm{CO}_{2}$ compressor station. Therefore, besides the increase of inter- 
nal consumption of heat due to regeneration of the solvent also internal consumption of electricity increases due to driving $\mathrm{CO}_{2}$ compressors.

Table 1: Selected results of simulative analysis of $\mathrm{CHP}$ plant integrated with $\mathrm{CO}_{2}$ processing unit and waste heat recovery installation $[5,6]^{*)}$.

\begin{tabular}{|c|c|c|c|}
\hline $\begin{array}{l}\text { Unit consumption of heat for regeneration of } \\
\text { solvent, } q_{r e g}, \mathrm{MJ} / \mathrm{kg} \mathrm{CO} 2\end{array}$ & 4.0 & 3.4 & 3.15 \\
\hline $\begin{array}{l}\text { Unit consumption of chemical energy of fuel } \\
\text { with reference to heat by the consumers, } \\
E_{\text {ch int }} / Q_{\text {con }}, \mathrm{J} / \mathrm{J}\end{array}$ & 1.3499 & 1.2395 & 1.2006 \\
\hline $\begin{array}{l}\text { Increase of unit consumption of chemical en- } \\
\text { ergy of fuel in comparison with reference } \\
\text { CHP plant, }\left(E_{\text {ch int }}-E_{\text {ch ref }}\right) / Q_{\text {con }}, \mathrm{J} / \mathrm{J}\end{array}$ & 0.1834 & 0.0730 & 0.0341 \\
\hline $\begin{array}{l}\text { Unit production of electricity with reference } \\
\text { to heat by the consumers, } E_{\text {el }} \text { int } / Q_{\text {con }}, \mathrm{J} / \mathrm{J}\end{array}$ & 0.3898 & 0.3579 & 0.3467 \\
\hline $\begin{array}{l}\text { Increase of unit production of electricity } \\
\text { in comparison with reference CHP plant, } \\
\left(E_{\text {el int }}-E_{\text {el ref }}\right) / Q_{\text {con }}, \mathrm{J} / \mathrm{J}\end{array}$ & 0.0452 & 0.0133 & 0.0021 \\
\hline $\begin{array}{l}\text { Increase of internal unit consumption of } \\
\text { electricity due to } \mathrm{CO}_{2} \text { processing unit, } \\
\left(\varepsilon_{\text {el int }} E_{\text {el int }}-\varepsilon_{\text {el ref }} E_{\text {el ref }}\right) / Q_{\text {con }}, \mathrm{J} / \mathrm{J}\end{array}$ & 0.0537 & 0.0493 & 0.0478 \\
\hline $\begin{array}{l}\text { Deficit of the electricity production in the in- } \\
\text { tegrated CHP plant, }\left|-\Delta E_{\text {el int }}\right| / Q_{c o n}, \mathrm{~J} / \mathrm{J}\end{array}$ & -0.0085 & -0.0360 & -0.0457 \\
\hline $\begin{array}{l}\text { Increase of the consumption of chemi- } \\
\text { cal energy of fuel charging the produc- } \\
\text { tion of electricity in replaced power plant, } \\
\Delta E_{c h p p} / Q_{c o n}, \mathrm{~J} / \mathrm{J}\end{array}$ & 0.0254 & 0.1078 & 0.1368 \\
\hline $\begin{array}{l}\text { Index of chemical energy savings with } \\
\text { reference to heat by the consumers, } \\
\left|-\Delta E_{\text {ch } \text { int }}\right| / Q_{\text {con }}, \mathrm{J} / \mathrm{J}\end{array}$ & 0.342 & 0.323 & 0.308 \\
\hline
\end{tabular}

*) All values in Tab. 1, except the unit consumption of heat for regeneration of solvent, have been calculated with reference to heat by the consumers.

Basing on the results of simulation analysis of power plant integrated with post-combustion $\mathrm{CO}_{2}$ capture the increase of internal consumption of electricity due to compression of $\mathrm{CO}_{2}$, as well as the increase of additional production of electricity in cogeneration with heat have been evaluated. The differences between them for the particular unit consumption of regenerative heat $(4.0,3.4,3.15)$ are negative values (Tab. 1$)$. It means that 
by the assumption of $E_{\text {elcon }}=$ idem (demand for electricity by consumers must be kept, similarly as demand for heat by consumers $Q_{c o n}=$ idem) the balance of electricity requires additional production in a replaced system power plant, causing the additional consumption of chemical energy of fuel.

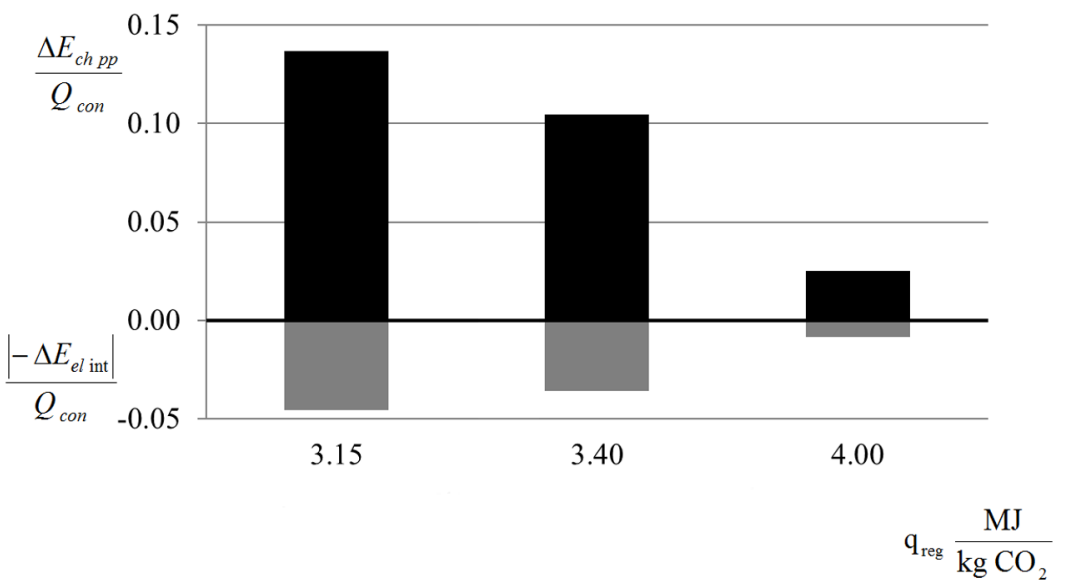

Figure 5: System effect of decreasing the deficit of the electricity production in the CHP plant: $\Delta E_{c h p p}$ - chemical energy of fuel in replaced integrated power plant charging the production of electricity closing the balance, $Q_{c o n}$ - heat loco consumers, $-\Delta E_{e l C H P}$ - deficit of electricity production, $q_{r e g}$ - unit consumption of heat for regeneration of solvent.

Figure 5 presents both deficit of electricity concerning CHP plant (the least value concerns $q_{r e g}=4.0 \mathrm{MJ} / \mathrm{kg} \mathrm{CO}_{2}$ ) and additional consumption of chemical energy of fuels charging the production of electricity in replaced power plant closing its balance. Similarly as in the previous cases it is clear that thanks to cogeneration we may observe a partial compensation of severe consequences of the worse coefficient of the unit consumption for regenerative purpose. In the case of the highest value of unit consumption of heat regeneration of solvent the deficit of electricity is the lowest. The lowest is also the increase of additional consumption of chemical energy of fuel in replaced integrated power plant.

Additional argument concerning the partial compensation of the increased internal consumption of heat thanks to cogeneration is showed in Fig. 6, where the relative reduction of the index of chemical energy savings in comparison with the reference CHP plant is presented. The lowest relative reduction of primary energy savings corresponds with the highest unit 


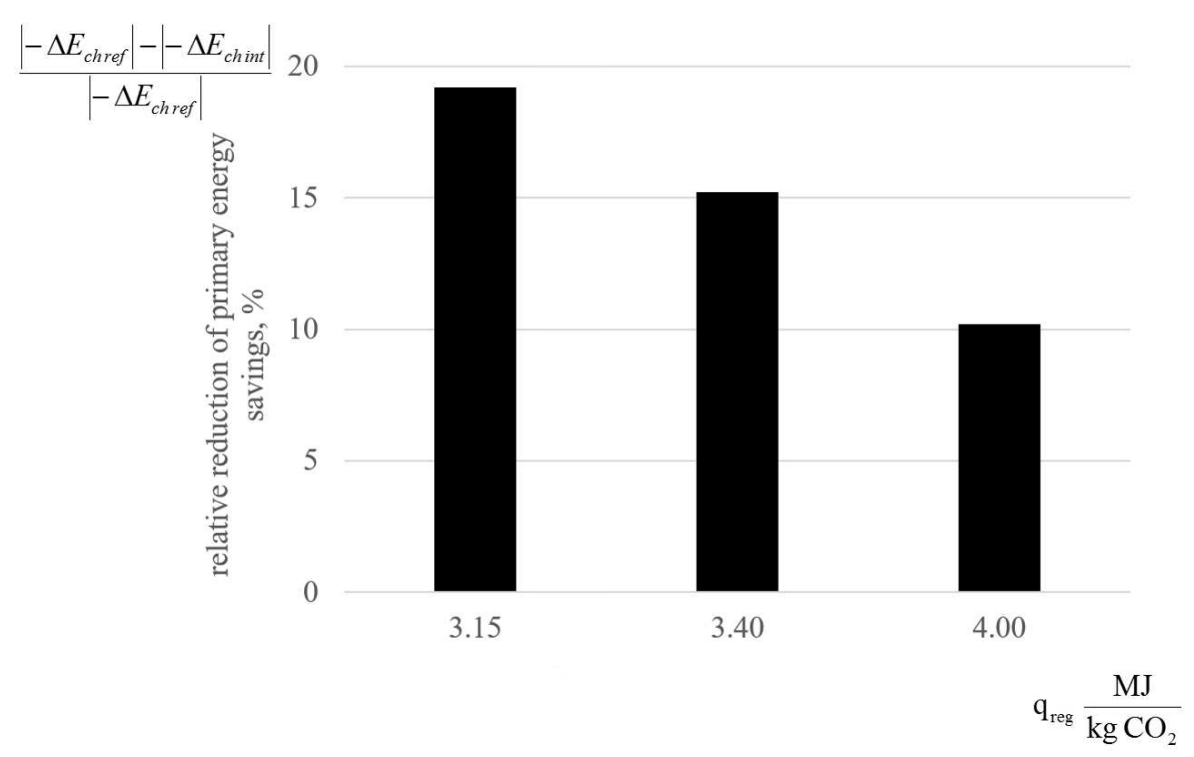

Figure 6: Relative reduction of primary energy savings due to additional consumption of heat for regeneration of solvent in the $\mathrm{CO}_{2}$ processing unit: $\mid-\Delta E_{\text {chref }} /$ - energy savings of fuel concerning reference CHP plant, $\mid-\Delta E_{\text {chint }} /$ - energy savings of fuel corresponding the CHP plant integrated with CPU, $q_{r e g}$ - unit consumption of heat for regeneration of solvent.

consumption of heat for the solvent regeneration. It does not indicate that the worse amine $\mathrm{CPU}\left(q_{r e g}=4.0 \mathrm{MJ} / \mathrm{kg} \mathrm{CO} \mathrm{CO}_{2}\right)$ the better, because in this case the consumption of chemical energy of fuel in the CHP integrated with amine CPU is the largest $\left(E_{\text {ch int }} / Q_{\text {con }}=1.3499 \mathrm{~J} / \mathrm{J}-\right.$ Tab. 1$)$. It may only indicate that thanks to cogeneration of heat production we may observe less severe consequences of the worse energy efficiency of CPU installation. This effect does not take place in the separate production of heat.

\section{Conclusions}

The presented problem, characterizing additional positive effects of CHP plants, is rarely exposed as an advantage of cogeneration technology. Already the first example concerning the partial compensation of heat losses during transmission of heat to industrial or municipal consumers, mentioned in literature [1], indicates clearly that heat losses during the transmission of heat from the CHP plant are less severe in comparison with the 
transmission from the heat-generating plant. Generally the positive effects of cogeneration are observed not locally in a CHP plant but within the frame of the national energy system. It means that the index of savings of chemical energy of fuel in comparison with separate production of heat and electricity is an adequate measure of the effectiveness in the case of heat and electricity cogeneration. At this point two additional remarks have to be mentioned. First of all, the system effects of primary energy reduction connected with cogeneration should be investigated for the CHP plants that have been already internally optimized, e.g., by means of the coefficient of the share of cogeneration [21]. Secondly, the proposed within the paper methodology concerning heat losses during the transmission of heat can only be used for the centralized cogeneration systems, thus within the wide range of small-scale cogeneration solution (e.g., micro-CHP based on the gas boiler with ORC module [22]) the presented approach cannot be applied.

Trigeneration realized in cooperation with absorption chiller is the second example in which system approach is needed for interpreting the useful effects. The savings of the chemical energy of fuel growth with the grows of the power to heat ratio and with decreasing the COP of absorption chiller. If the first reason is natural, the second one has a system character and results from the production of electricity in cogeneration with heat delivering the absorption chiller which partially replaces the production of electricity in the system power plant. The growing tendency of energy savings with the decreasing of COP of absorption chiller should explain that thanks to cogeneration we have less severe consequences due to the worse coefficient of performance of absorption chiller.

In a CHP plant integrated with amine post-combustion $\mathrm{CO}_{2}$ processing unit there is not only an increase of internal consumption of heat but also an increase of the internal consumption of electricity. Therefore, on the one hand we have an increase of electricity cogeneration due to additional demand for heat delivered to regeneration of solvent and on the other hand the increase of internal consumption of electricity concerning the driving of the $\mathrm{CO}_{2}$ compressors. In the considered case this causes the deficit in electricity balance of the CHP plant covered by the system power plant. Similarly as in trigeneration thanks to cogeneration of heat and electricity there is to be observed an effect of less severe consequences due to high value of the coefficient of unit consumption of heat for regeneration purposes of the solvent. 
Summing up these considerations it can be noticed that thanks to combined heat and power plants the increase of internal consumption of heat relates to the system effect of less severe consequences in comparison with separate production of heat and electricity. Examples presented in this paper confirm this conclusion.

Acknowledgements This work was carried out and financed within the frame of statutory research fund of the Faculty of Power and Environmental Engineering of the Silesian University of Technology in Gliwice (Poland).

Received 24 February 2017

\section{References}

[1] Szargut J.: Influence of the efficiency of heat transmission on energy effectiveness of CHP plant. Gospodarka Paliwami i Energia 4(1992), 3-5 (in Polish).

[2] ZIĘBIK A.: Cogeneration of heat and power combined with production of cooling agent. Gospodarka Paliwami i Energia 11(2003), 2-6(in Polish).

[3] ZięBik A., Hoinka K.: Energy Systems of Complex Buildings. Springer Verlag, London 2013.

[4] Lund H., VAd Mathiesen B.: The role of carbon capture and storage in a future sustainable energy system. Energy 44(2012), 469-476.

[5] ZięBIK A., Budnik M., LiszkA M.: Thermodynamic indices assessing the integration of coal- fired CHP plants with post-combustion CO2 processing unit (CPU). Energ. Convers. Manage. 73(2013), 389-397.

[6] ZięBik A., Budnik M., Liszka M.: Energy effectiveness of heat and electricity cogeneration integrated with amine processing unit. Energetyka, 68(2015), 5, 331339 .

[7] Horlock J.H.: Cogeneration - Combined Heat and Power(CHP). Thermodynamics and Economics. Krieger Publishing Company, Malabar 1997.

[8] Szargut J., Zı̨̇BIK A.: Fundamentals of Thermal Engineering. PWN, Warszawa 2000 (in Polish).

[9] Szargut J., ZIĘBIK A.: Cogeneration of heat and electricity - CHP. Polish Academy of Sciences. Division Katowice. Katowice - Gliwice 2007 (in Polish).

[10] Recknagel H., Sprenger E., Honman W., Schramek E.R.: Heating and Air Conditioning. Guidebook. EWFE, Gdańsk 1994 (in Polish).

[11] Fisher K. S., SEARCy K. et al.: Advanced amine solvent formulations and process integration for near-zero $\mathrm{CO}_{2}$ capture success. Grant No.: De-FG02-06ER84625 US Department of Energy - National Energy Technology Laboratory. Trimeric Corporation, Buda 2007. 
[12] Mangalapally H.P., Hasse H.: Pilot plant experiments for post combustion carbon dioxide capture by reactive absorption with novel solvents. Energy Proced. 4(2011), 1-8.

[13] Ogawa T., Ohashi Y., Yamanaka S., Miyaike K.: Development of carbon dioxide removal system from the flue gas of coal fired power plant. Energy Proced 2009, 1(2009), 1, 721-724.

[14] Kuramochi T., Ramírez A., FaAiJ A., Turkenburg W: Post-combustion CO2 capture from part-load industrial NGCC-CHPs: Selected results. Energy Proced. 1(2009), 1, 1395-1402.

[15] Global CCS Institute: CO2 capture technologies. Post Combustion Capture, 2011. www.cdn.globalccsinstitute.com/sites/default/files/publications/29721/co2capture-technologies-pcc.pdf (accessed 21 Nov.15).

[16] MHI's Energy Efficiency flue gas $\mathrm{CO}_{2}$ Capture Technology and Large Scale CCS Demonstration test at coal-fired Power Plants in USA. Mitsubishi Heavy Industries, Techn. Rev. 48(2011), 1.

[17] Eswaran S., Wu S., Nicolo R.: Advanced Amine-based $\mathrm{CO}_{2}$ Capture for Coal-fired Power Plants. Coal-Gen 2010. www.hitachipowersystems.us/technical_papers/index.html (accessed 21.Nov.16)

[18] Final Report CASTOR (CO2 from Capture to Storage): Project report, Apr. 2011. www.cordis.europa.eu/documents/documentlibrary/12477 2011EN6.pdf (accessed 21.Nov.16).

[19] Advanced Coal Power Systems with $\mathrm{CO}_{2}$ Capture: EPRI's CoalFleet for Vision, 2011. Update, a summary of Technology Status and Research, Development and Demonstrations, 2011 Technical Report. www.epri.com/ abstracts/Pages/ProductAbstract.aspx?productIdij000000000001023468 (accessed 21.Nov.16).

[20] Thermoflex version 22. Thermoflex Inc., www.thermoflex.com

[21] ZięBik A., GŁadysz P.: Optimal coefficient of the share of cogeneration in the district heating system cooperating with thermal storage. Arch. Thermodyn. 32(2011), $3,71-87$.

[22] Wajs J., Mikielewicz D., Bajor M., Kneba Z.: Experimental investigation of domestic micro-CHP based on the gas boiler fitted with ORC module. Arch. Thermodyn. 37(2016), 3, 79-94. 